\title{
Hypertrophic cardiomyopathy: a common disease with a good prognosis Five year experience of a district general hospital
}

\author{
LEONARD M SHAPIRO^, ALEXANDER ZEZULKA \\ From the Cardiac Department, Dudley Road Hospital, Birmingham
}

SUMMARY The manifestations and workload in a district general hospital cardiac unit of 39 unselected cases of hypertrophic cardiomyopathy over a five year period are reported. The "typical" form with asymmetrical septal hypertrophy and a gradient was found in only one third of patients, serious ventricular arrhythmias were probably no more common than in the general population, and no deaths occurred during a relatively short follow up (mean $3 \cdot 1$ years). It is concluded that although hypertrophic cardiomyopathy occupies a not insignificant proportion of cardiac workload, unselected cases presenting to a district general hospital represent a relatively mild disease without a grave prognosis.

Hypertrophic cardiomyopathy is characterised by idiopathic left ventricular hypertrophy. ${ }^{1}$ Nevertheless, the diagnosis encompasses a wide range of abnormalities and there are many unanswered questions, including its incidence and importance as a contributor to a community's cardiac disability. Large clinical studies have been described ${ }^{2-4}$ from centres where patients have been specifically referred with an established diagnosis because of the known interest of the unit. They report a high incidence of serious ventricular arrhythmias and sudden death with a poor long term prognosis. ${ }^{5}$ Our experience, however, is different with regard to clinical presentation, arrhythmias, and mortality. The purpose of this paper was to consider the manifestations and caseload from unselected cases of hypertrophic cardiomyopathy in a district general hospital cardiac unit.

\section{Patients and methods}

The West Birmingham health district has a population of about 320000 . The cardiac unit, based at Dudley Road Hospital, also receives patients from Hereford and Burton on Trent.

During routine adult clinical practice about 6000 new outpatients were seen and 2000 patients were admitted for cardiac catheterisation during a 5 year period (1977-82). The diagnosis of hypertrophic car-

^Present address: Cardiac Department, Brompton Hospital, London SW3 6HP. Accepted for publication 9 August 1983 diomyopathy was based on typical clinical features, ${ }^{2}$ and findings on $M$ mode echocardiography, ${ }^{6}$ and left ventriculography. ${ }^{7}$ The diagnosis was made by noninvasive methods in 16 , but as it is difficult to differentiate hypertrophic cardiomyopathy without a gradient from secondary left ventricular hypertrophy by clinical and $M$ mode echocardiographic means, ${ }^{8}$ secondary causes were excluded in 23 by cardiac catheterisation and left ventriculography.

Cardiac symptoms of angina, syncope, exertional dyspnoea, and palpitations and a family history of the disease or sudden death were recorded. The physical findings, especially an ill sustained arterial pulse, a cardiac impulse with a left ventricular nature or palpable fourth heart sound (atrial beat), murmurs, and added heart sounds were noted.

\section{ELECTROCARDIOGRAPHY}

The 12 lead electrocardiograms recorded at the time of diagnosis were analysed for atrial enlargement, ${ }^{9}$ ST segment depression, $T$ wave inversion, and the voltage criteria of left ventricular hypertrophy. ${ }^{10}$ In all patients one or more $\mathbf{4 8}$ hour periods of ambulatory electrocardiographic monitoring were performed (Oxford Medilog and Reynolds Pathfinder system) and evaluated for supraventricular and ventricular arrhythmias. ${ }^{11}$

\section{CARDIAC CATHETERISATION}

For diagnostic purposes, 23 patients underwent right and left heart catheterisation and left ventricular and 
coronary angiography using standard techniques. A left ventricular outflow gradient was considered present if more than a $30 \mathrm{~mm} \mathrm{Hg}$ pressure gradient was shown by simultaneous inflow (transseptal) and aortic (retrograde) pressure monitoring at rest or during provocation (with amyl nitrate and Valsalva manoeuvre).

\section{ECHOCARDIOGRAPHY}

A standard $M$ mode study was performed and septal and posterior wall thickness were measured $(\mathrm{cm})$ at end diastole ( $R$ wave on the electrocardiogram). Left ventricular hypertrophy was considered present if either the septum or posterior wall thickness exceeded $1.3 \mathrm{~cm}$ (outside two standard deviations from normal) and severe if more than $1.8 \mathrm{~cm} .{ }^{8}$ Hypertrophic cardiomyopathy was diagnosed in the presence of two or three of the following features: asymmetrical septal hypertrophy (septum to posterior wall ratio equal to or greater than $1 \cdot 5: 1$ ), systolic anterior motion of the mitral valve, or mid-systolic closure of the aortic valve. ${ }^{6}$

\section{Results}

Hypertrophic cardiomyopathy was diagnosed in 39 consecutive patients-that is $2 \%$ of the total and $8 \%$ of the angina investigations and $0.7 \%$ of the total outpatients. They were aged 15 to 76 (mean $55 \pm 7$ ) and 22 were women; the clinical details are shown in the Table. Ten were asymptomatic, including four diagnosed during family screening, three for investigation of a murmur, and three during population screening. ${ }^{12}$ Twelve had a family history of hypertrophic cardiomyopathy and two of sudden death. Only two patients had no abnormal cardiac signs, but two had only a systolic murmur and one added sounds alone.

The electrocardiogram was normal in three, and 32 showed a variable degree of left ventricular hypertrophy with left atrial enlargement in 23 . On ambulatory monitoring 12 had supraventricular arrhythmias (established atrial fibrillation in six), two had ill sustained ventricular tachycardia, and frequent $(<30 /$ hour) unifocal and multifocal ventricular extrasystoles were noted in five and four respectively.

On echocardiography only 13 (33\%) had asymmetrical septal hypertrophy but a further nine had a ratio greater than $1 \cdot 3: 1 ; 21(54 \%)$ showed systolic anterior motion of the mitral valve and $16(41 \%)$ had midsystolic closure of the aortic valve. Echocardiographic evidence of hypertrophy was present in all but three patients, two of whom showed angiographic apical hypertrophy. ${ }^{13}$

Cardiac catheterisation was performed in 23 (59\%) patients. A gradient (30 to $165 \mathrm{~mm} \mathrm{Hg}$ ) was noted in eight (five at rest and three provoked). Left ven-
Table Clinical features of 39 patients with hypertrophic cardiomyopathy

\begin{tabular}{|c|c|}
\hline $\begin{array}{l}\text { Symptoms } \\
\text { None } \\
\text { Angina } \\
\text { Absent } \\
\text { Typical exertion } \\
\text { Atypical } \\
\text { Dyspnoea (NYHA) } \\
\text { I } \\
\text { II } \\
\text { III and IV } \\
\text { Syncope } \\
\text { Palpitation }\end{array}$ & $\begin{array}{r}10 \\
18 \\
16 \\
5 \\
16 \\
15 \\
8 \\
9 \\
12\end{array}$ \\
\hline $\begin{array}{l}\text { Signs } \\
\text { None abnormal } \\
\text { Ill sustained pulse } \\
\text { Cardiac impulse } \\
\text { Atrial beat } \\
\text { Left ventricular } \\
\text { Systolic murmur } \\
\text { Third or fourth heart sound }\end{array}$ & $\begin{array}{r}2 \\
18 \\
11 \\
18 \\
31 \\
33\end{array}$ \\
\hline $\begin{array}{l}\text { Electrocardiogram } \\
\text { Normal } \\
\text { Left ventricular hypertrophy } \\
\text { ST-T changes } \\
\text { Supraventricular tachycardia } \\
\text { Ventricular tachycardia } \\
\text { Frequent ventricular extrasystoles } \\
(>30 \mathrm{~h}) \\
\text { Unifocal } \\
\text { Multifocal }\end{array}$ & $\begin{array}{l}3 \\
34 \\
25 \\
12(6 \mathrm{AF}) \\
2 \\
\\
5 \\
4\end{array}$ \\
\hline $\begin{array}{l}\text { Echocardiogram } \\
\text { Septum/posterior wall ratio } 1.5: 1 \\
\text { Systolic anterior motion of the mitral valve } \\
\text { Midsystolic aortic valve closure } \\
\text { Left ventricular hypertrophy } \\
\text { Mild }(>1.3 \mathrm{~cm}<1.8 \mathrm{~cm}) \\
\text { Severe }(>1.8 \mathrm{~cm})\end{array}$ & $\begin{array}{l}13 \\
21 \\
16 \\
21 \\
15\end{array}$ \\
\hline
\end{tabular}

NHYA, New York Heart Association classification.

triculography showed myocardial hypertrophy in all, and, in addition, mitral regurgitation was seen in six, systolic cavity elimination in 15 , and an angulated diastolic cavity in six. Projection of contrast in the interstices of the columnae carnae was noted in 18, and five had residual apical contrast at end systole. Five patients had significant occlusive coronary artery disease (more than $70 \%$ narrowing of one or more vessels).

During follow up from six months to five years (mean 31) no deaths occurred.

\section{Discussion}

Since its first recognition in the late 1950 s $^{14} 15$ hypertrophic cardiomyopathy has remained a source of continuing controversy. ${ }^{1617}$ Much of this is due to the many diagnostic criteria applied, especially as to the importance of left ventricular outflow tract gradients and asymmetrical septal hypertrophy. While these are common features, hypertrophic cardiomyopathy is characterised by idiopathic left ventricular hypertrophy, and, using this as the principal 
diagnostic feature, we identified a wide range of patients. While all had idiopathic left ventricular hypertrophy, only a third fulfilled the traditional diagnostic criteria of asymmetrical septal hypertrophy and a gradient. Two of the three classical physical signs (ill sustained arterial pulse, atrial beat, and systolic murmur 6 ) were present in $72 \%$ of these patients, however, and in $87 \%$ the electrocardiogram showed left ventricular hypertrophy. We found that the echocardiographic diagnostic criteria were not particularly helpful in patients with equivocal signs and electrocardiogram because these are based on septal hypertrophy and evidence of a gradient, but the presence of hypertrophy of some form was present in almost all. In those in whom non-invasive tests were inconclusive, to facilitate the diagnosis and exclude other causes of left ventricular hypertrophy, cardiac catheterisation and left ventriculography were performed. Cross sectional echocardiography is probably the current method of choice for detecting regional left ventricular wall hypertrophy, ${ }^{8}$ but was not available during this study.

Using these diagnostic criteria we have shown that hypertrophic cardiomyopathy is a relatively common diagnosis and occupies a not insignificant amount of cardiac workload. Clinical studies describe hypertrophic cardiomyopathy as a disease with a poor long term prognosis ${ }^{18}$ due to serious ventricular arrhythmias. 1920 Our experience, however, is different. No deaths occurred during follow up, which contrasts with a quoted annual mortality in excess of $2 \%$, and serious ventricular arrhythmias were probably no more common than quoted for the general population. ${ }^{21}$ While our sample size and follow up were small, these differences could be accounted for in several ways. Unlike the original clinical descriptions in relatively young patients with a mean age of 25.7 years, "2 "typical" hypertrophic cardiomyopathy may be found in the older patient, ${ }^{22}$ as in our study, but postmortem studies show that hypertrophic cardiomyopathy may also be an incidental finding in those dying from other causes. ${ }^{23}$ Patients at risk from sudden death may have "malignant" family histories, ${ }^{24}$ but many are young and asymptomatic-for example, Maron et al. ${ }^{25}$ showed that in 78 sudden deaths, 45 had no functional limitation, of whom $71 \%$ were less than 30 years old. In comparison, only $36 \%$ of our patients had a family history and only $21 \%$ were less than 30 years old, and possibly those at high risk had already died.

This and other studies of unselected populations show that left ventricular hypertrophy may often be found, ${ }^{26}$ that hypertrophic cardiomyopathy often occurs in a relatively mild or asymptomatic form, and a wide range of disease may be found.1227 Our patients must be representative of the disease mani- festation in a community even though probably a large proportion remain undiagnosed. Therefore differences in clinical manifestation compared with quoted series must be attributed to selection criteria. The implications of this study, in spite of a relatively small sample and follow up, are, firstly, that the mortality of these patients does not appear to be grossly different from normal and, secondly, that while sudden death may occur in patients with apparently mild disease (especially children), the diagnosis of this condition in adults does not necessarily imply a grave prognosis. The diagnosis may encompass a wide range of disease, and if physical signs and electrocardiogram are not typical the $M$ mode echocardiographic features of asymmetrical septal hypertrophy and systolic anterior motion of the mitral value are not usually present. The most common echocardiographic feature was the presence of hypertrophy of the posterior wall or septum, or both. We suggest that if this is present in a patient with equivocal physical signs and electrocardiogram (without a secondary cause of hypertrophy) there is a high probability of a diagnosis of hypertrophic cardiomyopathy.

We thank Dr Shyam Singh for permission to report patients under his care.

\section{References}

1 Goodwin JF. The frontiers of cardiomyopathy. $\mathrm{Br}$ Heart f 1982; 48: 1-18.

2 Braunwald E, Lambrew CT, Rockoff SD, Ross J Jr, Morrow AG. Idiopathic hypertrophic subaortic stenosis: 1, A description of the disease based upon an analysis of 64 patients. Circulation 1964; 29 and 30 (suppl IV): 3-19.

3 Goodwin JF, Hollman A, Cleland WP, Teare D. Obstructive cardiomyopathy simulating aortic stenosis. $\mathrm{Br}$ Heart f 1960; 22: 403-14.

4 Cohen J, Effat H, Goodwin JF, Oakley CM, Steiner RE. Hypertrophic obstructive cardiomyopathy. $\mathrm{Br} \mathrm{Heart} \mathrm{f}$ 1964; 26: 16-32.

5 McKenna WJ, Goodwin JF. The natural history of hypertrophic cardiomyopathy. Current problems in cardiology. vol. VI, no. 4. Chicago and London: Year Book Medical Publishers, 1981.

6 Doi YL, McKenna WJ, Gehrke J, Oakley CM, Goodwin JF. M-mode echocardiography in hypertrophic cardiomyopathy: diagnostic criteria and prediction of obstruction. Am f Cardiol 1980; 45: 6-14.

7 Simon AL, Ross J Jr, Gault JH. Angiographic anatomy of the left ventricle and mitral valve in idiopathic hypertrophic subaortic stenosis. Circulation 1967; 36: 852-7.

8 Shapiro LM, McKenna WJ. Distribution of left ventricular hypertrophy in hypertrophic cardiomyopathy: a cross-sectional echocardiographic study. $\mathcal{F}$ Am Coll Cardiol 1983; 2: 437-44.

9 Bethesda conference on optimal electrocardiography. Task Force 1: standardization of terminology and interpretation. Am f Cardiol 1978; 41: 130-45. 
10 Sokolow M, Lyon TP. The ventricular complex in left ventricular hypertrophy as obtained by unipolar precordial and limb leads. Am Heart $f$ 1949; 37: 161-86.

11 Ryan M, Lown B, Horn H. Comparison of ventricular ectopic activity during 24-hour monitoring and exercise testing in patients with coronary heart disease. $N$ Engl f Med 1975; 292: 224-9.

12 Shapiro LM. A prospective study of heart disease in diabetes mellitus. $Q \mathcal{F}$ Med 1983 (in press).

13 Yamaguchi H, Ishimura T, Nishiyama S, et al. Hypertrophic nonobstructive cardiomyopathy with giant negative $T$ waves (apical hypertrophy): ventriculographic and echocardiographic features in 30 patients. Am $\mathcal{f}$ Cardiol 1979; 44: 401-12.

14 Teare D. Asymmetrical hypertrophy of the heart in young adults. Br Heart $\mathcal{F}$ 1958; 20: 1-8.

15 Brock R. Functional obstruction of the left ventricle (acquired aortic subvalvular stenosis). Guy's Hosp Rep 1957; 106: 221-38.

16 Goodwin JF. Hypertrophic cardiomyopathy: a disease in search of its own identity. Am $\mathcal{F}$ Cardiol 1980; 45: 17780.

17 Bulkley BH. Idiopathic hypertrophic subaortic stenosis afflicted: idols of the cave and the market place. Am $\mathcal{F}$ Cardiol 1977; 40: 476-9.

18 McKenna W, Deanfield J, Faruqui A, England D, Oakley C, Goodwin JF. Prognosis in hypertrophic cardiomyopathy: role of age and clinical, electrocardiographic and hemodynamic features. Am f Cardiol 1981; 47: 532-8.

19 Savage DD, Seides SF, Maron BJ, Myers DJ, Epstein SE. Prevalence of arrhythmias during 24-hour electrocardiographic monitoring and exercise testing in patients with obstructive and nonobstructive hyper- trophic cardiomyopathy. Circulation 1979; 59: 866-75.

20 McKenna WJ, England D, Doi YL, Deanfield JE, Oakley C, Goodwin JF. Arrhythmias in hypertrophic cardiomyopathy: I. Influence on prognosis. $\mathrm{Br}$ Heart $\mathrm{f}$ 1982; 46: 168-72.

21 Clarke JM, Hamer J, Shelton JR, Taylor S, Venning GR. The rhythm of the normal human heart. Lancet 1976; ii: 508-12.

22 Whiting RB, Powell W J Jr, Dinsmore RE, Sanders CA. Idiopathic hypertrophic subaortic stenosis in the elderly. $N$ Engl f Med 1971; 285: 196-200.

23 Davies MJ, Pomerance A, Teare RD. Pathological features of hypertrophic obstructive cardiomyopathy. $f$ Clin Pathol 1974; 27: 529-35.

24 Maron BJ, Lipson LC, Roberts WC, Savage DD, Epstein SE. "Malignant" hypertrophic cardiomyopathy: identification of a subgroup of families with unusually frequent premature death. Am $\mathcal{f}$ Cardiol 1978; 41: 1133-40.

25 Maron BJ, Roberts WC, Epstein SE. Sudden death in hypertrophic cardiomyopathy. A profile of 78 patients. Circulation 1982; 65: 1388-94.

26 Savage DD, Garnson RJ, Kannel WB, et al. Prevalence, characteristics and correlates of echocardiographic left ventricular hypertrophy in a population-based samplepreliminary findings: The Framingham study [Abstract]. Circulation 1982; 66 (suppl II): 63.

27 Bjarnason I, Jonsson S, Hardarson T. Mode of inheritance of hypertrophic cardiomyopathy in Iceland. Echocardiographic study. Br Heart $\mathcal{F}$ 1982; 47: 122-9.

Requests for reprints to Dr Leonard M Shapiro, Cardiac Department, Brompton Hospital, Fulham Road, London SW3 6HP. 